\title{
Role of Platelet Indices in Differentiating Hypoproductive and Hyperdestructive Thrombocytopenia
}

\author{
Shaheena Parveen and Mourouguessine Vimal* \\ Department of Pathology, Sri Manakula Vinayagar Medical College and Hospital, Puducherry, India
}

\begin{abstract}
Background: During evaluation of thrombocytopenic patients, it is essential to identify the etiology, whether it is due to hypoproduction or hyperdestruction which will have impact on the management. Aim of study is to evaluate the variation and relationship of platelet indices in hypoproductive and hyperdestructive thrombocytopenia patients.

Methods: A cross sectional study for a period of 2 months on Patients with thrombocytopenia. Platelet count, Plateletcrit (PCT), Platelet Distribution Width (PDW) and Mean Platelet Volume (MPV) and relevant clinical details of the thrombocytopenic patients were collected and tested for statistical significance by unpaired t test.

Results: This study included 120 patients of thrombocytopenia who were classified into hypoproductive (26 cases) and hyperdestructive (94 cases). The mean platelet count in hypoproduction group is $75.9 \pm 36.4$ and in hyperdestruction group is $79.6 \pm 36.3$ with a $\mathrm{P}$ value of 0.64 . The mean MPV in hypoproduction group is $10.17 \pm 1.3$ and in hyperdestruction group is $12.3 \pm 0.9$ with a significant $P$ value of 0.05 . The mean PDW in hypoproduction group is $19.7 \pm 5.4$ and in hyperdestruction group is $19.3 \pm 4.2$ with a P value of 0.7 . The mean PCT in hypoproduction group is $0.06 \pm 0.03$ and in hyperdestruction group is $0.08 \pm 0.1$ with a $\mathrm{P}$ value of 0.2 .

Conclusion: Mean platelet volume may provide useful information in discriminating the hypoproductive and hyperdestructive thrombocytopenia. Interpretation of platelet indices can help the thrombocytopenic patients in the initial management and can avoid invasive investigations.
\end{abstract}

Keywords: Thrombocytopenia, Platelet Indices, Mean Platelet Volume, Plateletcrit, Platelet Distribution Width

\section{Introduction}

Thrombocytopenia is a significant finding in hospitalized patients which may be often missed if platelet parameters are not evaluated routinely. Platelet counts below 1,50,000 define thrombocytopenia, but they do not reveal the underlying pathology. ${ }^{[1]}$ During evaluation of these patients, it is essential to identify the etiology, whether it is due to hypoproduction or hyperdestruction and this will have impact over the proper management of the patients.

For a long time Bone marrow aspiration remained the gold standard method for evaluating the cause of thrombocytopenia. But this procedure is invasive, time consuming as well as carries an overt risk of bleeding diathesis in critical thrombocytopenia cases. Serology (For infectious diseases), Platelet associated Immunoglobulin G(PAIgG) and Molecular markers for Disseminated Intravascular coagulation(DIC) are used in evaluating thrombocytopenic patients which are relatively costly. ${ }^{[2]}$ Previously platelet count was the only vital information available about this small blood element. But recently automated blood cell analyzers have made it possible to measure various Platelet indices, such as Mean Platelet
Volume (MPV), Platelet Distribution Width (PDW), and Plateletcrit (PCT) with a simple Complete blood count and these parameters may provide some valuable information. ${ }^{[3]}$ Recent years studies have come up to explore the utility of these parameters in routine clinical practice.

This study attempts to find the usefulness of these platelet indices in the initial evaluation of patients with thrombocytopenia by assessing their variation in different clinical scenarios and to assess their sensitivity and specificity.

\section{Aim:}

- To evaluate the variation in platelet indices in establishing clinical correlation in patients presenting with thrombocytopenia.

- To study the relationship of platelet indices with respect to the underlying mechanism of thrombocytopenia.

\section{Materials and Methods}

This study is a cross sectional study for a period of 2 months in a tertiary care centre. Various Platelet parameters including Platelet count, Plateletcrit (PCT), Platelet Distribution Width (PDW) and Mean Platelet Volume 
(MPV) of the thrombocytopenic patients were collected from the routine laboratory blood investigations done in the Autoanalyser (ABX PENTRA DX 120) and documented. Correlation with routine peripheral smear findings of the respective cases was done. Relevant clinical details and available investigations including serological results of the patients were included.

\section{Inclusion criteria}

All adult Patients aged $>18$ years of both sexes with a platelet count of less than $1,50,000$.

\section{Exclusion criteria1)}

Patients aged less than 18 years. \& 2) Patient on antiplatelet drugs and other medications causing thrombocytopenia were excluded.

\section{Statistical analysis}

The Data collected wereanalysed using the software Statistical Package for Social Sciences (SPSS) program version 24 (IBN. Chicago, USA). Measurements of laboratory data platelet parameters of patients with thrombocytopenia in the two different hypoproductive and hyperdestuctive group were statistically tested by unpaired t test. A $p$ value less than 0.05 was considered statistically significant.

\section{Results}

This study included 120 patients of thrombocytopenia who were classified into hypoproductive and hyperdestructive group. In the hypoproductive we had 26 cases and in the hyperdestruction there were 94 cases. The distribution of cases in each subgroup and comparison of the distribution with similar studies were shown in table.1. The mean platelet count in the hypoproduction group is $75.9 \pm 36.4$ and in the hyperdestruction group is $79.6 \pm 36.3$ with a $\mathrm{P}$ value of 0.64 . The mean MPV in the hypoproduction group is $10.17 \pm 1.3$ and in the hyperdestruction group is $12.3 \pm 0.9$ with a significant $\mathrm{P}$ value of 0.05 . The mean PDW in the hypoproduction group is $19.7 \pm 5.4$ and in the hyperdestruction group is $19.3 \pm 4.2$ with a $\mathrm{P}$ value of 0.7 . The mean PCT in the hypoproduction group is $0.06 \pm 0.03$ and in the hyperdestruction group is $0.08 \pm 0.1$ with a $P$ value of 0.2 . Mean values of different platelet indices and P-value in Hyper- destruction Immune thrombocytopenia and hypoproduction thrombocytopenia were shown in Table.2.

Table 1: The distribution of thrombocytopenia cases in each subgroup and comparison of the distribution with similar studies.

\begin{tabular}{|c|c|c|c|}
\hline Etiologies & $\begin{array}{l}\text { Katti et al }(23) \\
\text { Total cases }(\%)\end{array}$ & $\begin{array}{c}\text { Numbenjapon et al(24) } \\
\text { Total cases }(\%)\end{array}$ & $\begin{array}{l}\text { Present study } \\
\text { Total cases (\%) }\end{array}$ \\
\hline \multicolumn{4}{|c|}{ Hypoproduction } \\
\hline Aplastic anemia & - & $12(11.8 \%)$ & - \\
\hline Megaloblastic anemia & $08(8 \%)$ & $4(3.9 \%)$ & $11(9.2 \%)$ \\
\hline Leukemia and MDS & $06(6 \%)$ & $22(21.6 \%)$ & $2(1.7 \%)$ \\
\hline Others & - & - & $13(10.8 \%)$ \\
\hline \multicolumn{4}{|c|}{ Hyperdestruction } \\
\hline ITP & $4(4 \%)$ & $53(52 \%)$ & $3(2.5 \%)$ \\
\hline Dengue & $29(29 \%)$ & - & $26(21.7 \%)$ \\
\hline Scrub Typhus & - & - & - \\
\hline Malaria & $24(24 \%)$ & - & $8(6.7 \%)$ \\
\hline Chronic liver disease & $3(3 \%)$ & - & $20(16.7 \%)$ \\
\hline Sepsis & $4(4 \%)$ & $9(8.8 \%)$ & $6(5 \%)$ \\
\hline DIC & $2(2 \%)$ & - & - \\
\hline Others & $19(19 \%)$ & $2(2 \%)$ & $31(25.8 \%)$ \\
\hline Total & 100 & 102 & 120 \\
\hline
\end{tabular}

Table 2: Mean values of different platelet indices and P-value in Hypoproduction thrombocytopenia and Hyperdestruction thrombocytopenia

\begin{tabular}{|l|c|c|c|}
\hline Platelet indices & Hypoproduction & Hyperdestruction & P Value \\
\hline Platelet count $\left(\right.$ mean \pm SD) $\left(\times 10^{\%} / \mathrm{l}\right)$ & $75.9 \pm 36.4$ & $79.6 \pm 36.3$ & 0.64 \\
\hline MPV (mean \pm SD) $(\mathrm{fl})$ & $10.17 \pm 1.3$ & $12.3 \pm 0.9$ & 0.05 \\
\hline PDW (mean \pm SD) $(\mathrm{fl})$ & $19.7 \pm 5.4$ & $19.3 \pm 4.2$ & 0.7 \\
\hline PCT (mean \pm SD) $\%$ & $0.06 \pm 0.03$ & $0.08 \pm 0.1$ & 0.2 \\
\hline
\end{tabular}




\section{Discussion}

Platelet indices include Plateletcrit (PCT), Platelet Distribution Width (PDW) and Mean Platelet Volume (MPV). Though these parameters have been available from the routinely used blood cell counters in the laboratory, their exact role in application to clinical diagnosis has still not been fully established. ${ }^{[4]}$

Measurement of platelet indices in automated analysers has many advantages over manual estimation, as it is very simple, quick and inexpensive test which also eliminates the observer bias. ${ }^{[5,6]}$ Further in manual method, a delay between collection of blood and smear preparation, may change the platelet morphology and also artefactual increase in platelet diameter can occur because of increased adhesiveness with flattening of the platelets on the smears. ${ }^{[7]}$

Numbenjapon et $\mathrm{a}^{[8]}$ found that MPV was significantly higher in hyperdestruction group compared to hypoproductive thrombocytopenia. In hyper destructive thrombocytopenia, bone marrow compensates actively for the platelet loss and start releasing young larger platelets ("left shift") which tend to decrease in size during its 7-10 days life span ${ }^{[9]}$ In our study also we found a significant low $(10.17 \pm 1.3)$ mean MPV in the hypoproduction group than in the hyperdestruction group $(12.3 \pm 0.9)$

Ntaios et $\mathrm{al}^{[10]}$ found an increased MPV and PDW in Immune Thrombocytopenic Purpura (ITP). Kaito et al ${ }^{[2]}$ similarly found a significant increase in MPV and PDW in ITP than in Aplastic anemia. Similarly few studies found a high PDW can also result in hyper destructive thrombocytopenia because of the release of heterogenous population of platelets which vary in their size (anisocytosis). ${ }^{[11,12]}$ Both MPV and PDW are reliable tests in hyperdestructive thrombocytopenia and considered as tests of $100 \%$ sensitivity and specificity for the diagnosis of ITP. ${ }^{[13,14]}$ But in contrast, Tomito et $\mathrm{al}^{[15]}$ found a low MPV in hyperdestructive thrombocytopenia and Nakadate $\mathrm{H}$ et $\mathrm{al}^{[16]}$ and Baynes $\mathrm{RD}$ et $\mathrm{al}^{[17]}$ found no significant difference in the MPV and PDW between the hyperdestructive and hypoproductive thrombocytopenia. Bashir AB et al ${ }^{[18]}$ found significant differences in the MPV, PDW and PLT in patients with dengue infection and they suggested that these parameters can be used as probable indicators for dengue in endemic area. He also found a MPV $<9 \mathrm{fl}$ and high PDW $>13 \mathrm{fl}$ had a considerable sensitivity for dengue fever.

PCT is a representation of volume percent of platelets and its value is not altered by severity of thrombocytopenia of either hypoproductive or hyperdestructive etiology.

Shah et $\mathrm{al}^{[19]}$ found that increase in PDW and MPV. They also found increase in MPV in Ischemic heart disease patients.
In our study we did not find any significant difference in PDW between the two subgroups. But Shah et al ${ }^{[20]}$ and Borkataky et al ${ }^{[6]}$ found a higher PDW in hyperdestructive thrombocytopenia when compared to hypoproductive thrombocytopenia. Kaito et al ${ }^{[13]}$ suggested that a PDW value of more than $17 \mathrm{fl}$ and Ntaios et al ${ }^{[14]}$ suggested a value between 15 and 17 fldiscrimate this two subgroups. But $\mathrm{Xu}$ et $\mathrm{al}^{[21]}$ found a contrasting result of higher PDW values in the hypoproductive thrombocytopenia and attributed this as a result of significant dysplasia of hematopoiesis in the bone marrow in the hypoproductive group. The major disadvantage in these retrospective studies is that some had a smaller study population and other confounding factors that influenced the platelet volume. further the cut off values suggested by these studies have not been validated. ${ }^{[22,23]}$

Limitation of the study: The sample size in our study is small and further we had a limited number of cases 26 $(21.7 \%)$ in the hypoproduction category. This may limit its application when applied to a larger patient community.

\section{Conclusion}

The Mean platelet volume may provide some useful information in discriminating the hypoproductive and hyperdestructive thrombocytopenia. Thus interpretation of this platelet indice can help the patients to avoid unnecessary invasive investigations like bone marrow aspiration and unnecessary platelet transfusion. Further studies with large number of cases in each subgroupsare needed to explore the role of this useful platelet index in thrombocytopenia and also to find the diagnostic roleof platelet indices various other diseases.

\section{References}

1. Strauß G, Vollert C, von Stackelberg A, Weimann A, Gaedicke G, Schulze H. Immature platelet count: A simple parameter for distinguishing thrombocytopenia in pediatric acute lymphocytic leukemia from immune thrombocytopenia. Pediatr Blood Cancer. 2011 Oct 1;57(4):641-7.

2. Kaito K, Otsubo H, Usui N, Yoshida M, Tanno J, Kurihara $\mathrm{E}$, et al. Platelet size deviation width, platelet large cell ratio, and mean platelet volume have sufficient sensitivity and specificity in the diagnosis of immune thrombocytopenia. Br J Haematol. 2005 Mar;128(5):698-702.

3. Park Y, Schoene N, Harris W. Mean platelet volume as an indicator of platelet activation: methodological issues. Platelets. 2002 Sep;13(5-6):301-6.

4. Giovanetti TV, do Nascimento AJ, de Paula JP. Platelet indices: laboratory and clinical applications. Rev Bras Hematol E Hemoter. 2011;33(2):164-5.

5. Beyan C, Kaptan K, Ifran A. Platelet count, mean platelet volume, platelet distribution width, and plateletcrit do not correlate with optical platelet aggegation responses in 
healthy volunteers. J Thromb Thrombolysis. 2006 Dec 5;22(3):161-4.

6. Borkataky S, Jain R, Gupta R, Singh S, Krishan G, Gupta $\mathrm{K}$, et al. Role of platelet volume indices in the differential diagnosis of thrombocytopenia: a simple and inexpensive method. Hematology. 2009 Jun;14(3):182-6.

7. Nelson RB, Kehl D. Electronically Determined Platelet Indices in Thro $\mathrm{rn}$ bocytopen ic $\mathrm{Pa}$ tien ts. Cancer. 1981;48:954-956.

8. Numbenjapon T, Mahapo N, Pornvipavee R, Sriswasdi C, Mongkonsritragoon W, Leelasiri A, et al. A prospective evaluation of normal mean platelet volume in discriminating hyperdestructive thrombocytopenia from hypoproductive thrombocytopenia. Int $\mathrm{J}$ Lab Hematol. 2008 Oct;30(5):408-14.

9. Kottke-Marchant K, Corcoran G. The laboratory diagnosis of platelet disorders: an algorithmic approach. Arch Pathol Lab Med. 2002;126(2):133-146.

10. Ntaios G, Papadopoulos A, Chatzinikolaou A, Saouli Z, Karalazou P, Kaiafa G, et al. Increased values of mean platelet volume and platelet size deviation width may provide a safe positive diagnosis of idiopathic thrombocytopenic purpura. Acta Haematol. 2008;119(3):173-7.

11. Rajantie J, Javela K, Joutsi-Korhonen L, Kekomäki R. Chronic thrombocytopenia of childhood: use of noninvasive methods in clinical evaluation. Eur J Haematol. 2004 Apr 1;72(4):268-72.

12. Gardner FH, Bessman JD. Thrombocytopenia due to defective platelet production. Clin Haematol. 1983 Feb;12(1):23-38.

13. Kaito K, Otsubo H, Usui N, Yoshida M, Tanno J, Kurihara E, et al. Platelet size deviation width, platelet large cell ratio, and mean platelet volume have sufficient sensitivity and specificity in the diagnosis of immune thrombocytopenia. Br J Haematol. 2005 Mar;128(5):698-702.

14. Ntaios G, Papadopoulos A, Chatzinikolaou A, Saouli Z, Karalazou P, Kaiafa G, et al. Increased values of mean platelet volume and platelet size deviation width may provide a safe positive diagnosis of idiopathic thrombocytopenic purpura. Acta Haematol. 2008;119(3):173-7.

15. Tomita E, Akatsuka JI, Kokubun Y. Differential diagnosis of various thrombocytopenias in childhood by analysis of platelet volume. Pediatr Res. 1980 Feb;14(2):133-7.

16. Nakadate H, Kaida M, Furukawa S, Ishii M, Higashihara M. Use of the Platelet Indices for Differential Diagnosis of Pediatric Immune Thrombocytopenic Purpura (ITP). Blood. 2008 Nov 16;112(11):4557-4557.

17. Baynes RD, Lamparelli RD, Bezwoda WR, Gear AJ, Chetty N, Atkinson P. Platelet parameters. Part II. Platelet volumenumber relationships in various normal and disease states. South Afr Med J Suid-Afr Tydskr Vir Geneeskd. 1988 Jan 9;73(1):39-43.

18. Bashir AB, Saeed OK, Mohammed BA, Ageep AK. Role of Platelet Indices in Patients with Dengue Infection in Red Sea State, Sudan. [cited 2015 Dec 5]; Available from: http:// www.ijsr.net/archive/v4i1/SUB15582.pdf

19. Shah AR, Chaudhari SN, Shah MH. Role of Platelet Parameters in Diagnosing Various Clinical Conditions. Hypertension. 2011;89:11-13.

20. Shah AR, Chaudhari SN, Shah MH. Role of Platelet Parameters in Diagnosing Various Clinical Conditions. Natl J Med Res. 2013;3(2):162-5.

21. Xu R-L, Zheng Z-J, Ma Y-J, Hu Y-P, Zhuang S-H. Platelet volume indices have low diagnostic efficiency for predicting bone marrow failure in thrombocytopenic patients. Exp Ther Med. 2013 Jan;5(1):209-14.

22. Leader A, Pereg D, Lishner M. Are platelet volume indices of clinical use? A multidisciplinary review. Ann Med. 2012 Dec;44(8):805-16.

23. Katti T, Mhetre S, Annigeri C. How far are the platelet indices mirror image of mechanism of thrombocytopeniamystery still remains? Int J Adv Med. 2014;1(3):200.

*Corresponding author:

Dr Mourouguessine Vimal, No.21, Narmatha street, Vasanth nagar, Muthialpet, Puducherry - 605003 INDIA

Phone: +91 9994083575

Email: drvimalm@gmail.com

Date of Submission : 16.02.2017

Date of Acceptance : 07.03.2017

Financial or other Competing Interests: None.

Date of Publication : 14.06.2017 